\title{
Cine Real: etnografia de uma sala de cinema para trabalhadores
}

\section{Cine Real: ethnography of a movie theater for workers}

\section{Cláudio Bertolli Filho}

Livre-docente; docente no Programa de Pós-Graduação em Comunicação e no Programa de Pós-Graduação em Educação para a Ciência da Universidade Estadual Paulista.

<cbertolli@uol.com.br>

\section{RESUMO}

O consumo social e cultural dos produtos cinematográficos ainda é pouco estudado pelos pesquisadores brasileiros, originando uma significativa lacuna sobre a importância do "ir ao cinema", especialmente no referente aos grupos sociais subalternos. Este estudo utiliza os recursos e conceitos propostos pela autoetnografia, sendo que os dados analisados foram obtidos mediante uma extensa série de diálogos, presenciais ou mediados por computador, travados entre cinco indivíduos que, acompanhados por suas famílias, frequentaram no decorrer da década de 1960 o Cine Real, localizado no município de São Caetano do Sul, estado de São Paulo. A frequência semanal ao cinema resultou em um conjunto de experiências culturais e estéticas que agitava o cotidiano das famílias trabalhadoras e deixou significativas marcas na trajetória de vida dos membros do grupo que colaborou com a pesquisa.

\begin{abstract}
Social and cultural consumption of film products still is rarely studied by Brazilian researchers, creating a significant gap on the importance of "going to the movie theater", especially in the case of subordinate social groups. The study uses the features and concepts proposed by the autoethnography, and the data analyzed were collected through an extensive series of dialogues, face-to-face meeting or computermediated, fought between five individuals who, accompanied by their families, attended during the decade of 1960 the Cine Real, located in the municipality of São Caetano do Sul, São Paulo State. Weekly frequency to the movie theater resulted in a set of cultural and aesthetic experiences that stirred the daily lives of working families and left significant marks in the life trajectory of the group members who collaborated with the research.
\end{abstract}

Keywords: Autoethnography. Movie Theater. Workers.

Após um longo período, as pesquisas quegeralmente têm sido qualificadas como "estudos sobre o cinema" ramificaram-se, passando a explorar não só a construção de sentidos arquitetados no processo da produção cinematográfica e as bilheterias, mas também o perfil do público e as condições que permitem os sujeitos sociais de estarem nas salas de exibição e assistir as películas. Assim, paralelamente ao enfoque do consumo grupal dos conteúdos fílmicos, a sala de cinema, ao mesmo tempo como espaço arquitetônico e território simbólico 
ganhou interesse por parte dos estudiosos, gerando um ainda pequeno, mas promissor, número de estudos que buscam englobar a complexidade de experiências que podem ser sintetizadas pelo ato de "ir ao cinema".

Nesta perspectiva, as primeiras iniciativas acadêmicas sobre o"ir ao cinema" centraram os interesses nas salas de cinema localizadas nas capitais estaduais, sobretudo nas instalações frequentadas pelas camadas mais privilegiadas da sociedade, onde eram apresentados filmes recentes e de sucesso de público. Tributários da perspectiva histórica, tais estudos primam por ressaltar as características arquitetônicas dos prédios que abrigavam as salas de cinema e as características sociais do público que as frequentavam, contando para tanto principalmente com fontes impressas representadas por matérias jornalísticas e obras memorialísticas e biográficas, privilegiando a experiência individual e também de pequenos grupos que compareciam nos recintos que projetavam filmes (Simões, 1990; Gastal, 1999; Aguiar, 2002).

Em anos mais recentes, o profícuo diálogo estabelecido entre os campos da Comunicação e da Antropologia tem propiciado um novo vigor dos estudos tematizados pela presença grupal às salas de cinema. As novas concepções de cultura, especialmente aquela incorporada pela antropologia comprometida com as propostas da fenomenologia tem instigado enfoques inovadores, inclusive no referente às condicionantes de consumo coletivo dos produtos midiáticos.

A conjugação dos métodos histórico e etnográfico nos estudos da Comunicação tem favorecido o enfoque das salas de cinema como um espaço no qual se justapõem várias funções: lazer, sociabilidade, conhecimento do mundo e experiência estética, dentre outras possibilidades. Com esses apoios, Guimarães (2013) analisou um cinema localizado na região central de São Paulo como ponto de encontro e de consumo fílmico do público gay da cidade, enquanto que Kishimoto (2009), com maior detalhismo e rigor acadêmico, focou as salas de cinema visitadas pela colônia japonesa radicada em São Paulo, ambientes que eram utilizados para (re)lembrar a cultura do país natal, reforçar os laços de solidariedade da comunidade e travar novos contatos sociais entre os membros da comunidade nipônica e seus descendentes.

No contexto das pesquisas, praticamente ainda nada se registrou sobre o ato de "ir ao cinema" por parte do proletariado urbano nacional, sendo que a autoetnografia abre-se como uma possibilidade inovadora para o estudo deste grupo. Isto porque, uma extensa parcela das experiências próprias das camadas subalternas, especialmente as ocorridas em décadas passadas, foram precariamente preservadas pelas fontes documentais "tradicionais", 
permanecendo apenas na memória ou, como querem alguns estudiosos, nas representações individuais e coletivas alimentadas pelo pretérito efetivamente vivido (Bosi, 1994).

O ato de dissertar oralmente sobre o presente e sobre o tempo pretérito e a busca de significados do que é dito têm coagido, com imprecisão, a aproximação e às vezes identificação entre a autoetnografia e as propostas da antropologia interpretativa, que tem como personagem de proa Clifford Geertz. Comparada ao conceito de "descrição densa", as críticas à autoetnografia confundem ambos os conceitos e alimentado uma série de asseverações as quais fluem para um posicionamento comum: a possibilidade de fuga da "realidade", portanto algo contrário à cientificidade esperado de um estudo acadêmico, principalmente quando o pesquisador não dispõe do respaldo de outras modalidades documentais que não seja aquela alimentada pela fala própria ou alheia. Nesse sentido, a autoetnografia tem sido objeto de oposições baseadas, sobretudo nas críticas que foram desferidas contra as propostas geertzianas (Del Cairo; Jaramillo Marín, 2008; Reynoso, 2005). No entanto, as pesquisas que levam em consideração inclusive a participação direta e não velada do autor têm resultado em avaliações mais judiciosas. Como instrumento de "organização das próprias experiências", a autoetnografia e a autoantropologia relativizam as clássicas fronteiras entre sujeito-pesquisador e objeto de averiguação têm sido analisadas com maior rigor, sendo Strathern (2014) uma das principais representantes deste movimento.

Apesar disso, a maior ênfase concedida às subjetividades dos indivíduos imersos no conjunto de experiências vividas no cotidiano em relação à concepção de subjetividades metafísicas tem permitido que a autoetnografia alcance a posição de um importante método de compreensão do homem, da sociedadee de seus mecanismos de funcionamento. Além disso, a autoetnografia favorece a constituição de novos crivos para o pensar acadêmico sobre a relação entre sujeito pensante e objeto de estudo, desvelando um horizonte no qual ganha destaque sentidos ainda pouco revelados da experiência humana, primeiramente individual e, em seguida, grupal (Watson, 1993; Clifford, 1998).

O empenho em somar, não sem contradições, a percepção do investigador com as de outros sujeitos sociais foi claramente destacada por dois pesquisadores que, após registrarem os fundamentos da proposta autoetnográfica, concluíram nos seguintes termos:

É assim que se possa entender o autoetnografia como uma estratégia que prioriza e descreve a experiência vivida e as variações no modo de outorga de sentido. O pesquisador é parte da "cultura" 
que investiga, está socializado, pondo em jogo elementos pessoais e sociais. Portanto, é uma estratégia experiencial. Nisto emergem temores próprios do pesquisador em mostrar-se, assumindo que as críticas teóricas e metodológicas pretendem represar o afetivo são uma forma de "proteção" das experiências do próprio pesquisador. A autoetnografia significa dar conta do que se escuta, do que se sente e do compromisso não só com o tema, mas também com a ação, ao reconstruir a própria experiência. Como já se insinuou, nisto ocorre uma dupla implicação: o pesquisador "é arte e parte" do fenômeno que quer narrar (Scribano e Sena, 2009, p. 8)'.

A partir desse posicionamento, o autor manteve contato com outras pessoas que, como ele, na primeira parte da década de 1960, viveu a infância e/ ou a adolescência em uma área então denominada vila Nova, hoje amalgamada com a vizinha vila Gerty, recebendo o nome-síntese de vila Nova Gerty, um bairro periférico do município de São Caetano do Sul que, por sua vez, distancia-se 11 km do centro da cidade de São Paulo, capital do estado com o mesmo nome. Foram cinco pessoas (uma mulher e quatro homens), incluindo o pesquisador, que têm em comum não só a proximidade de idades e de local de moradia há quase cinco décadas passadas, mas também pertenciam às famílias proletárias que, no período analisado, tinham como um dos principais polos de lazer a presença no Cine Real, a sala de projeção de filmes localizado no centro do bairro. Delineou-se assim o objetivo deste texto: discutir as experiências individuais e familiares articuladas com a assídua frequência ao cinema e seus reflexos, pelo menos parciais, na trajetória de vida de cada um dos envolvidos na pesquisa.

O contar das experiências vividas há meio século por um grupo que hoje tem idade entre 58 e 65 anos de vida constituiu-se em uma aventura que, em certos momentos, fazia com que as confissões de cada um gerassem ora conflito ora verdadeiras catarses coletivas. Reviver um passado povoado de alegrias e tristezas tendo como pano de fundo as condições de vida da classe proletária também gerou emoções intensas, piadas insanas, lágrimas e, sobretudo, solidariedade às crianças e adolescentes que um dia fomos. $\mathrm{O}$ contato entre os

1 "Es así que se puede entender la auto-etnografía como una estratégia que prioriza y describe la propia experiencia vivida y las variaciones en el modo de otorgarle sentido. El investigador es parte de esa "cultura" que investiga, esta socializado com ella, se pone em juego elementos personales y sociales. Por lo tanto es uma estrategia experiencial. Emergen los propios temores en tanto hay um mostrarse del investigador, asumiendo que las críticas teóricas y metodológicas que pretenden poner um dique a lo afectivo son también un modo de "protección" a la aparición de las vivencias del mismo. La autoetnografía significa dar cuenta de lo que se escucha, lo que se siente y del propio compromiso no solo con la temática sino con la acción, al reconstuir la propia experiencia. Como ya se há insinuado, hay una doble implicación: el investigador "es arte y parte" del fenómeno que quiere narrar". 
cinco personagens, que a partir de agora serão invocados como "colaboradores" deu-se inicialmente por encontros pessoais na residência da mãe de um dos envolvidos e, em seguida, os diálogos tiveram continuidade por meio de e-mails, chamadas telefônicas e, sobretudo, pelo Skype.

Para cumprir a tarefa proposta pela pesquisa, em um primeiro momento optou-se por enquadrar os personagens no cenário da vila Nova e no contexto cultural típico do proletariado sulsancaetanense para, em seguida, apresentar a experiência deles e de suas famílias quando frequentavam o Cine Real.

\section{São Caetano do Sul e a vila Nova}

Denominada no final do século XVI como fazenda Tijucuçu, o território a sudoeste da então vila de São Paulo foi logo em seguida doada à Ordem Beneditina que rebatizou as terras recebidas como fazenda São Caetano. A qualidade pobre do terreno fez com que seus primeiros habitantes a abandonassem, sendo o território habitado mais por indígenas do que por ocupantes brancos, caindo em esquecimento até o ano de 1877, quando tornou-se um núcleo colonial imperial para o qual foram enviadas famílias de imigrantes oriundos do sul da Itália, os quais rebatizaram a área com o nome de São Caetano deThiene, em homenagem à cidade italiana de onde eram oriundos. Apesar de aí se estabelecerem com a proposta de se dedicarem à vinicultura, os recém-chegados logo constataram que o solo era argiloso, portanto impróprio para a prática agrícola, dedicando-se a partir de então aos trabalhos de olaria, cerâmica e carvoaria.

No início do século passado, o sucesso das empresas de cerâmica e a disponibilidade de ligação com São Paulo por rodovia e por estrada de ferro favoreceram que São Caetano atraísse novos habitantes - sobretudo de origem ibérica e, em menor escala, nipônica -, e a instalação de várias indústrias de beneficiamento de milho e amendoim, inclusive duas unidades fabris que garantiram a prosperidade econômica local: a Cerâmica São Caetano e uma grande unidade das Indústrias Reunidas Francisco Matarazzo, dedicada à produção de óleos (Martins, 2002).

O pequeno, mas importante parque industrial e o comércio local permitiram que, em 1947, depois de duas décadas de tentativa, o antigo núcleo de imigrante que havia se tornado distrito de São Bernardo do Campo ganhasse autonomia administrativa, tornando-se um município de apenas $15 \mathrm{~km}^{2}$, momento no qual adotou a designação oficial de São Caetano do Sul. Graças à política desenvolvimentista que emblematizou o governo do presidente 
Juscelino Kubitschek (1956-1961), São Caetano e os dois municípios vizinhos, Santo André e São Bernardo do Campo, passaram a corporificar o ABC paulista, a principal região industrial de todo o país, contando São Caetano com várias indústrias de ponta com matrizes nos Estados Unidos e na Europa, inclusive uma unidade da fábrica General Motors e outra da siderúrgica Mannesmann.

A concentração industrial, especialmente automobilística, alterou profundamente o perfil da população sulsancaetanense. No final da década de 1950, o município contava com cerca de 60 mil habitantes, o dobro de habitantes computados no início da mesma década, fazendo com que os imigrantes estrangeiros e seus descendentes, que reclamavam para si a posição de elite municipal, ganhassem como concorrentes os migrantes nordestinos que chegaram à cidade, fazendo com que São Caetano fosse considerada "a maior cidade nordestina fora do nordeste", passando a fazer parte da Região Metropolitana que tem sua sede na cidade de São Paulo.

Refletindo as transformações da cidade, a vila Nova, localizada na periferia da cidade, perdia seus espaços verdes, chácaras e terrenos baldios, os quais foram substituídos por novas residências, um cemitério e uma favela (cujos habitantes e barracos, por volta de 1967, foram transferidos, sob escolta militar, no espaço temporal e no sigilo de uma única madrugada, para São Bernardo do Campo). As ruas, que eram de terra batida, foram sendo pavimentadas com paralelepípedos e mais tarde com asfalto, chegando às residências água encanada e esgoto subterrâneo. Nas ruas centrais, passaram a correr ônibus arcaicos e mal-conservados, cujas rotas conduziam os moradores da vila para o centro comercial e político do município e também para a cidade de São Paulo. Tais coletivos, sempre apinhados de passageiros a ponto de vários deles ficarem literalmente pendurados na parte externa do veículo, perpetuaram-se na memória dos colaboradores, pois ostentavam em sua parte interna cartazes com uma inscrição irônica: "quem não nasce para sofrer, não serve para viver".

No plano da cultura e do lazer, o município criava seus polos próprios. Times de futebol profissional, como a Associação Atlética São Bento e o Saad Esporte Clube movimentaram as tardes de domingo na cidade por uns poucos anos, enquanto que o futebol de várzea criava rivalidade entre os bairros. Desprovida de aparelhos de televisão e de geladeira, as famílias dedicavamse à audição de programas de rádio, sendo que a Rádio Cacique, inaugurada em 1958, tornou-se a voz privilegiada das questões locais, lançando para um efêmero estrelato duplas de cantores caipiras e, em seguida, grupos de músicos nordestinos. Para além disso, restavam poucas outras opções de lazer, como os bares onde se reuniam os homens à noite e nos finais de semana e as igrejas, 
onde as mulheres se encontravam, ou ainda os portões das residências, onde no final da tarde conversavam com as vizinhas. Para as crianças restavam as ruas, onde se reuniam para jogar bola, trocar figurinhas e contar vantagens.

No leque das opções de lazer, poucas outras possibilidades eram disponíveis. Para os menos afortunados economicamente, as esporádicas apresentações de circos mambembes e as romarias programadas segundo o calendário cristão eram viáveis. Outras práticas, no entanto, despontavam como exclusivas das elites locais, como a ida regular às raras lanchonetes, casas noturnas e restaurantes, e a prática de esportes no clube social local, dominado a mão de ferro pela elite dos velhos imigrantes.

Nesse cenário, a frequência às salas de cinema despontava como o principal lazer disponível para a camada proletária (Rufini, 1990) e, ainda mais, como significativa forma de discriminação dos habitantes do município. Consenso entre os colaboradores, cujas falas dão sentido a este texto, havia três tipos de sulsancaetanenses na primeira metade dos anos 60. Os "ricos e sofisticados", que frequentavam os cinemas do centro da cidade, como os cines Vitória, Max e Lido ou ainda que, sendo proprietários de automóveis, podiam se dar ao luxo de ir até os cinemas da cidade de São Paulo, sem ter problema de regressar às suas residências, já que os ônibus deixavam de circular à meianoite; os "pobres", assalariados de baixa renda que frequentavam os cinemas de bairro, já conhecidos como "pulgueiros", tais como o cine Átila, na vila Gerty, o Real na vila Nova, o Planalto, no bairro Barcelona e o Alvorada, próximo ao centro da cidade. Por fim, existia também o grupo dos "miseráveis", composto pelos mais pobres e pelos desempregados, que não tinham recursos suficientes para se tornar frequentador assíduo de um cinema e que só viam imagens projetadas na tela quando um pároco resolvia oferecer graciosamente à comunidade a projeção de filmes em locais abertos. Para atender a um público sempre crescente, em meados da década de 1960, São Caetano do Sul contava com mais de uma dúzia de salas de projeção, algumas delas, como os cines Max e Primax, com cerca de 2.500 assentos, sendo que a maioria acomodava em média 1.000 espectadores por sessão.

O cine Real foi inaugurado em 1961, na rua Nelly Pellegrino, via fronteiriça entre as então vila Gerty e vila Nova. Diferentemente dos cinemas dos "ricos", que contava com um saguão amplo e com decoração sofisticada e com o auditório com poltronas estofadas, o cine Real dispunha de um saguão acanhado e austero, rimando com uma sala de exibição sem qualquer atrativo e com cadeiras de madeira. De propriedade da família Santarelli, que possuía várias outras salas de cinema na cidade, o cine Real destacava-se também por 
dispor de 1.200 lugares, contando ainda com dois projetores da marca Triunfo. Igual a todas as salas do período, a parte frontal do cinema era recoberta por chamativos e coloridos cartazes que anunciavam as fitas que estavam sendo exibidas durante a semana ou que seriam projetados nas semanas seguintes (Relação de cinemas..., 2013; Moura; Lima; Nascimento, 2012).

É necessário destacar também que, igualmente a muitos outros cinemas de periferia, os filmes projetados eram antigos, sendo que a geração do autor pode assistir no cine Real filmes produzidos desde o advento do cinema sonoro até os realizados poucos anos antes de ser exibido para o público da vila Nova. Aqueles que desejavam se inteirar de filmes mais recentes, que estavam sendo comentados nas páginas dos jornais, tinham que obrigatoriamente dirigir-se aos cinemas "de ricos" do município ou ir até os principais cinemas de São Paulo, nos quais os ingressos eram mais caros.

\section{O ritual de ir ao cinema}

A frequência assídua à sala de exibição incorporava e ainda incorpora um ritual complexo que já foi assinalado por vários estudiosos do cinema (Rancière, 2013; Gabler, 2000; Canevacci, 1984). No entanto, tais autores pecaram por não dispensar maior atenção à questão no referente às classes subalternas, o mesmo acontecendo no referente às pesquisas nacionais, circunstância que impõe que boa parte das informações esteja preservada apenas nas recordações das pessoas, condição que confere ainda mais valor ao método da autoetnografia na realização deste estudo ${ }^{2}$.

No decorrer do período vistoriado, comparecer ao cinema no sábado à noite constituía-se em uma espécie de ritual para as famílias trabalhadoras, definindo-se também em um dos pontos altos de reforço dos laços de sociabilidade entre os moradores do bairro. A maior parte dos homens adultos trabalhava até o meio-dia do sábado nas fábricas e no setor comercial; quando chegavam em suas residências, dava-se início ao ritual, cuja primeira ação era o banho de cada um dos membros da família, sendo que, em regra, era o único banho tomado pelo chefe do clã durante a semana. Esse momento era crucial para as crianças mais rebeldes, pois a grande punição para elas era a ameaça de não acompanharem seus pais nesse programa familiar; na verdade, raramente

20 livro assinado por Barcinski e Finotti (1998), apesar de privilegiar a biografia de um diretor e ator de cinema, constitui-se em exceção, apresentando algumas informações fragmentadas sobre os cinemas suburbanos e seu público. 
elas eram impedidas de ir ao cinema, pois geralmente não havia onde e com quem deixa-las nas noites de sábado.

Os banhos eram seguidos de um jantar cujo cardápio diferenciava-se daquele adotado nos outros dias da semana, pois compostos de lanches ou pastéis comprados em bares e pastelarias. Em seguida, fizesse bom tempo ou chovesse, cada um colocava a melhor roupa; os homens de terno e gravata, as mulheres de vestidos mais requintados, saltos altos e penteados preparados para aquela ocasião, enquanto que os adolescentes e as crianças ostentavam os trajes que eram utilizados em poucas situações além da ida ao cinema, como casamentos, festas de aniversários, de fim de ano e ainda velórios.

Neste processo, vislumbra-se várias etapas da sociabilidade grupal. Primeiramente, a própria família unia-se para o desfrute de um momento de recreação coletiva, da mesma maneira que anos mais tarde o grupo postar-seia frente a um aparelho de televisão para assistir aos seus programas favoritos. Em seguida, na rota que partia da residência até a sala de projeção, a família juntava-se casualmente a outros grupos familiares conhecidos que seguiam na mesma direção, alimentando conversas que versavam sobre praticamente tudo, do estado da saúde das crianças e dos idosos até futebol, trabalho e fofocas nutridas pela vizinhança.

Já nas sempre longas filas para a compra dos bilhetes de ingresso na sala de espetáculo abria-se oportunidade para os adultos entabularem conversa com desconhecidos, mas que eram de alguma maneira vistos como próximos, já que com certeza moradores no bairro. Os mais jovens afastavam-se um pouco dos pais; os adolescentes agregavam-se por gênero, permitindo que os rapazes se identificassem pela escola que estudavam e/ou empregos que ocupavam, contando casos curiosos e proezas, enquanto admiravam o grupo formado pelas mocinhas que, por sua vez, tentavam corresponder, com certa indiscrição, aos olhares masculinos em meio a rizinhos encabulados. Para as crianças, além de brincadeiras improvisadas, era reservada uma missão especial: "furar a fila", isto é, ir até a proximidade do guichê de venda dos ingressos, esperar a oportunidade para se infiltrar na fila e assim comprar em pouco tempo ingressos para toda a família, operação que, de regra, era tolerada pelos adultos "enganados" pela petizada. A maior parte dos filmes anunciados era proibida para o público infantil, mas os gerentes do cinema não levavam a lei a sério, pois sabiam que o comparecimento ao espetáculo era um programa familiar e que as crianças não poderiam deixar de estar presente.

De posse dos ingressos, o grupo familiar dirigia-se à portaria do cinema e adentrava no saguão apinhado de gente, onde se deparavam com novas filas 
para a aquisição de pipoca, doces, balas e refrigerantes baratos, momento que era aproveitado para os adultos alimentarem novas conversas e também para os rapazes se aproximarem mais empolgadamente das garotas. Esta etapa era realizada até o momento em que eram abertas as portas do auditório; com as luzes acesas e ao som de músicas entoadas pela orquestra de Ray Conniff ou pela bigband Tabajara, cada família procurava animadamente as poltronas com posições mais privilegiadas para assistirem os filmes, em meio a conversas em tom alto, fazendo um dos colaboradores, lembrar que "parecia um mercado de peixe".

A congregação familiar sobrevivia por pouco tempo, já que os adolescentes masculinos novamente se reuniam nos fundos da sala, enquanto que os mais jovens brincavam em grupo por todo o recinto. Tais atividades se desenvolviam até o momento em que as luzes da sala eram gradualmente reduzidas e a música era interrompida e substituída pelo som de gongos que, soando por três vezes, anunciava o início da projeção dos filmes. Ocorria então um silêncio geral e a ocupação das últimas poltronas que ainda estavam livres por aqueles que chegavam atrasados ou que estavam no saguão do cinema comprando novos quitutes para consumo durante o filme. Nesse momento entravam em ação os "lanterninhas", funcionários contratados para fiscalizar os comportamentos na penumbra da sala, fazendo piscar a lanterna que portavam quando constatavam beijos prolongados ou a ação de mãos atrevidas, tendo o poder de expulsar do recinto as pessoas que insistiam em continuar com os atos tidos como imorais e, especialmente, aqueles que estivessem se comportando inadequadamente por estarem apresentando elevado estado etílico. Mesmo que proibido, os mesmos funcionários toleravam amigavelmente aqueles que teimavam fumar durante o espetáculo.

A sessão de cinema era composta por momentos específicos, prolongando-se das $19 \mathrm{~h} 30$ às 23 horas e, dependendo da extensão dos filmes, até uma hora mais tarde, já que ninguém precisava contar com condução para retornar ao lar e, o dia seguinte, era domingo, momento em que os trabalhadores poderiam dormir até mais tarde. Isto não impedia que a gerência dos cinemas cortassem propositalmente cenas dos filmes mais longos, para assim a sessão ser encerrada no horário que achasse conveniente.

As etapas ideais da sessão de filmes eram geralmente as seguintes: primeiramente a projeção de uma película que mais tarde seria enquadrada como "filme B", isto é, produções baratas que pouco superavam uma hora de duração, tematizada por tramas protagonizadas por cowboys, gangsteres, fantasmas, vampiros, cientistas ensandecidos, invasores espaciais e por qualquer 
aberração que chocava ou aterrorizava a plateia. Assim, sempre se esperava deparar-se na tela com antigas encenações protagonizadas por Edward G. Robinson, John Wayne, Boris Karloff, Bela Lugosi capitaneando uma legião de atores fadados ao esquecimento.

Finda a primeira película, as luzes eram acesas e tinha início o intervalo, o qual durava entre 20 ou 30 minutos, momento no qual era projetado um capítulo de seriados antigos, sendo lembrado pelo grupo de discussão Flash Gordon (Flash Gordon, 1938), Super-Homem (Superman, 1948), O homem foguete (King of the rocket man, 1949) e sobretudo Nacional Kid (National Kid, 1960-1961), além de seriados com os personagens Tarzan e Jim das Selvas. Este era a parte do espetáculo preferido pela garotada, não só pelos heróis que apareciam na tela, mas também porque tais seriados eram dublados, permitindo que mesmo os pequenos analfabetos, ou próximo disso, entendessem as tramas.

O intervalo poderia se prolongar caso o proprietário do cinema suburbano, buscando maximalizar os lucros, burlasse a soma que deveria ser paga às empresas distribuidoras dos filmes. Isto se dava quando um empresário possuía várias casas de espetáculo ou, por acordo com outro dono de cinema, predispunha-se a projetar os mesmos filmes na mesma noite em dois cinemas, invertendo a ordem de apresentação das películas. Nestes casos, era comum o próprio responsável por atuar junto às máquinas de projeção ser encarregado de, logo após o término da primeira projeção, apoderar-se das latas de filmes e rumar a pé ou de bicicleta até o outro cinema e voltar com um novo filme (Barcinski e Finotti, 1998). O fato de a família Santarelli ser proprietária de vários cinemas no município permitia que isto ocorresse com certa frequência, especialmente quando os dois filmes da sessão não eram de boa qualidade; isto fazia a alegria das crianças, pois o tempo do intervalo era estendido, abrindo espaço para a apresentação de dois ou até três capítulos seguidos dos seriados que elas tanto gostavam.

Pouco depois de finalizada a projeção do seriado, as luzes voltavam a serem apagadas e dava-se início à projeção do filme principal, o qual não se restringia à produções hollywoodianas, apesar de já serem estas as predominantes. Certamente para atender à demanda representada pelo público imigrante e por seus descendentes, era comum também a projeção de películas produzidas nos países ibéricos e na Itália, havendo ainda apresentações de filmes alemães, soviéticos (isto no período anterior ao golpe militar de 1964) e japoneses.

Graças ao diário preservado pela esposa de um dos colaboradores da pesquisa, alguns desses filmes puderam ser lembrados, além daqueles que ficaram na memória dos membros do grupo que forneceu informações para 
a realização deste artigo. A conjugação da fonte escrita com as informações lembradas por mais de um colaborador permite afirmar que, dentre as produções vistas no cine Real encontravam-se desde O cantor de jaz (The jazz singer, 1927), o primeiro filme sonoro da história cinematográfica, até Cidadão Kane (Citizen Kane, 1941), A um passo da eternidade (From here to eternity, 1951), Palavras ao vento (Written on the wind, 1956) e Dr. Fantástico (Dr. Strangelove, 1964), além das primeiras películas protagonizadas pelo agente James Bond.

Fora do circuito Estados Unidos/Inglaterra, o público chorava com fitas nacionais como O ébrio (1946) e Floradas na serra (1954), ria com as chanchadas estreladas por Oscarito, Grande Otelo e Costinha e com os inúmeros filmes estrelados por Mazzaropi.Também se sensibilizavam com os espanhóis Marcelino pão e vinho (Marcelino, pan y viño, 1955) e Um raio de luz (Un rayo de luz, 1960), que fizeram os atores mirins Pablito Calvo e Marisol astros cultuados inclusive pela garotada sulsancaetanense. Da mesma forma, películas italianas, principalmente as de cunho romântico, alcançaram sucesso na periferia do município, sendo a principal delas $A$ doce vida (La dolce vida, 1960) e, especialmente, Dio, como ti amo (Dio, come ti amo, 1966), antecedida pela produção ítalo-norte-americana Candelabro italiano (Rome adventure, 1960).

Findo o último filme, o clima de sonolência parecia dominar a plateia. Com bem menos barulhos e conversas que no início da noite, todos abandonavam a sala de cinema. Os menores já há muito haviam adormecido e eram carregados no colo pelos seus pais ou por irmãs mais velhas; as famílias caminhavam vagarosamente para suas casas, em um período no qual ainda não haviam maiores receios de serem vitimadas por atos criminosos. Também diferentemente de quando rumavam para o cinema, os aglomerados familiares voltavam para seus lares em quase-silêncio, evitando conversas mais longas com os vizinhos que também tinham ido ao cine Real.

As sessões de cinema não ocorriam todos os dias da semana, acontecendo apenas aos sábados, domingos e quartas-feiras. Nas projeções de domingo à tarde o público era bem menor, composto por jovens casais que namoravam "sério", isto é, que pretendiam se casar em breve e que, portanto, recebiam a permissão de irem sozinhos ao cinema ou de famílias que, por algum motivo, não puderam ir ao cinema no sábado. Tais sessões só lotavam quando ocorria a falta de energia na noite anterior, fato não muito raro em São Caetano nos primeiros anos da década focada, circunstância que obrigava a gerência a oferecer a todos que já havia adquirido o bilhete de ingresso um passe válido apenas para o dia seguinte. As sessões de domingo à noite e quarta-feira à 
noite eram pouco frequentadas e dizia-se que só os desocupados compareciam a elas, qualificação desabonadora no ambiente do proletariado.

\section{A experiência estética-cultural}

Entende-se por experiência estética a capacidade humana de, ao se deparar com determinadas situações e objetos comprometidos ou não com a arte, sensibilizar-se a ponto de vivenciar um conjunto de reações e pensamentos que podem ampliar as possibilidades de o sujeito se orientar no mundo. Invocada por Walter Benjamin como "iluminação profunda" e por Robert Musil como "outro estado", tais designações remetem a "um estado mental ou intelectual que definitivamente transcendem o comum cotidiano, mas insistem, ao mesmo tempo, no expressamente intramundano" (Bohrer, 2001, p. 18). As reações que compõem a experiência estética, especialmente no referente aos produtos gerados pelas empresas de comunicação são inclusive de ordem física e isto porque, no caso estudado, um filme fala para o corpo, instigando-o a (cor) responder aos apelos das imagens em movimento, sons e cores projetadas na tela (Kerckhove, 2009, p. 26).

Nesses termos, assistir semanalmente a dois filmes constituía-se em uma quebra da monotonia cotidiana da vida comprometida com o trabalho industrial, com as atividades domésticas, com as brincadeiras grupais, em suma, com os grandes e pequenos arranjos da existência proletária. Em um mundo relativamente fechado, no qual as conversas entre os membros da comunidade e as mensagens radiofônicas eram, de regra, as formas de conviver com um mundo mais amplo, o cine Real definia-se como uma forma mais abrangente de conhecer e experimentar a realidade distanciada de São Caetano e, certamente, também sonhar. Daí o silêncio respeitoso mantido quando se iniciava o filme e a punição aqueles que teimavam em perturbar as horas dedicadas à sessão cinematográfica; daí também os risos e lágrimas, os "uhs!!!" e "ohs!!" que acompanhavam as cenas mais tensas e chocantes que eram expostas na tela.

A possibilidade oferecida pelo cinema de o público desligar-se momentaneamente dos seus problemas cotidianos está longe de resultar naquilo que os críticos mais exaltados classificam como intento alienador da indústria cultural. Enquanto experiência estética e cultural, as mensagens midiáticas instigam seus receptores a refletir sobre suas próprias existências e, ainda mais, permitia que o público entrasse em contato, mesmo que mediado pelo meio de comunicação, com novas opções de vida, culturas e valores impossíveis de serem então conhecidos por outro meio, já que a própria 
aquisição e leitura de jornais era raro entre os trabalhadores que, geralmente só os compravam quando estavam desempregados e recorriam aos classificados para saber das vagas de trabalho disponíveis.

A experiência cinematográfica não se esgotava com o encerramento da sessão de cinema. As questões representadas nos filmes ocupavam uma parcela considerável das conversas travadas durante a semana. Um dos colaboradores, que então era adolescente, reportou-se ao fato de, quando sua família compareceu à exibição do filme Farrapo humano (The lost weekend, 1945), o qual discorre sobre instantes da vida de um alcoólatra, sua família e "várias vizinhas da minha mãe" identificaram-se com o enredo, já que seu pai, assim como vários chefes de família da rua em que morava, eram viciados em álcool tanto quanto o personagem interpretado por Ray Milland. Ainda segundo o mesmo depoente, o filme sensibilizou a tal ponto que as decisões apresentadas na trama fílmica passaram a instigar as conversas sobre como resolver o problema dos pais e maridos bêbados. Os filmes e os diálogos por eles alimentados nas ruas da vila Nova também serviam para que a vida fosse (re)pensada e (re) encaminhada.

Os portões das casas era o local preferido para as donas de casa se encontrarem e dialogarem sobre a vida, ganhando espaço privilegiado os filmes assistidos recentemente. As tramas românticas, tal como aquela explorada em E o vento levou (Gone with the wind, 1939) e Tarde demais para esquecer (An affair to remember, 1958) não só sensibilizaram a plateia como também alimentaram os sonhos e os diálogos de muitas mulheres. Uma colaboradora lembrou que, já no início da adolescência, havia brigado com uma amiga a ponto de se estapearem, porque insistia que ambos os filmes "não eram bons", pois no primeiro, Scarlett O'Hara e Rhett Butler "não terminaram juntos", enquanto que no segundo, Nickie Ferrante "só resolveu namorar a sério" Terry McKay quando esta ficou aleijada. Passados mais de meio século desde que assistiu a ambos os filmes e conflituou com a amiga, a colaboradora parece ainda se mostrar inconformada com o desfecho das fitas, invocando com precisão os nomes dos personagens das duas películas.

O cine Real, como portal para representações de realidades mais abrangentes disponibilizadas à comunidade, também dispunha de filtros para a seleção dos conteúdos cinematográficos que poderiam ser exibidos. Se a busca de lucros por parte da família Santarelli associava-se aos interesses dos distribuidores de filmes, é provável que outros motivos também concorressem para que um filme fosse ou não levado ao público. Definido como um cinema da e para a família do bairro, é provável que algumas produções fossem vetadas para exibição por motivos puramente morais. Mesmo que a regra implícita 
adotada pelo cine Real era apresentar filmes que contavam com vários - ou muitos - anos desde sua realização, até o final do período avaliado nem os registros preservados no diário anteriormente mencionado nem a memória dos colaboradores desta pesquisa permitem afirmar que filmes gerados pelo Nouvelle Vague francesa ou pelo Cinema Novo brasileiro foram apresentados, assim como uma as produções com cenas e temáticas mais ousadas assinadas por diretores italianos e norte-americanos.

Houve também nos diálogos entre os colaboradores que levavam a momentos que poderiam ser classificados como de autoirritação. Isto porque a memória preserva cenas que pareciam cruciais para a constituição de medos na infância e que, em alguns casos se prolongaram na vida adulta. Perguntas sem respostas como "você se lembra do título daquele filme no qual um pirata foi morto e enterrado, e depois nasceu uma árvore sobre a cova e o morto encarnou a dita árvore que passou o filme inteiro andando e matando as pessoas?"; "qual era o título daquele filme russo que a toda hora aparecia uma rosa de pedra?" e "sabe aquele filme que contava as horas finais da vida dos passageiros de um ônibus que caiu num precipício e todos morreram?" Mas também ocorreram confissões mais claras, como a de um depoente que disse que, ainda criança, assistiu os episódios $A$ invasão dos incas venusianos da série National Kid e a partir de então passou a ter pesadelos com os invasores. Mais ainda, o mesmo depoente disse que, em anos recentes, numa madrugada deparou-se com a exibição dos mesmos episódios em uma emissora de televisão interiorana e descobriu que ainda alimentava os antigos medos a ponto de não reunir coragem suficiente para reassisti-los. Em resposta a essa confissão, outros colaboradores desta pesquisa brindou o assustado colega com a frase "Celacanto provoca maremoto!", a qual ficou famosa pelo fato de o endoidecido Dr. Sanada a proferir aos gritos em várias cenas do seriado japonês.

Se a experiência estética-cultural alimentada pelo consumo fílmico suscita amores e medos, também é possível registrar que tal experiência contribui também para a formação da personalidade (López Quintás, 2010). Foi unânime entre os colaboradores a ideia de que os filmes assistidos no cine Real foram fundamentais em suas formações; as concepções de amor, honra, heroísmo, reação frente a adversidade, sentido da vida e da morte, dentre tantos outros elementos mencionados, foram formatadas - mas não ditadas - a partir dos conteúdos expostos nas telas do cinema. Enredos fílmicos lembrados em toda extensão ou simplesmente a partir cenas fragmentárias permanecem nas lembranças de todos e são estas peças e fragmentos cinematográficos que se 
mantêm como elementos inspiradores das ações e pensamentos assumidos no cotidiano de suas vidas.

Um dos membros do grupo de colaboradores afirmou: "acredito que sou o que sou por ter assistido aqueles filmes!"Esta sentença não implica a admissão que a indústria cultural "fez a cabeça" ou alienou as crianças e adolescentes que hoje são idosos, ou próximos disso. Não. Mesmo que alguns colaboradores desconheçam os fundamentos teóricos que embasam suas observações, parece claro que os valores expostos na tela foram e continuam sendo objetos de reflexão e reavaliação, servindo de alguma forma como pontos de apoio para a fluição das sensibilidades e da tomada de decisões na esfera do cotidiano. Neste sentido, pode-se inferir que o posicionamento do grupo se aproxima dos ensinamentos de García Canclini:

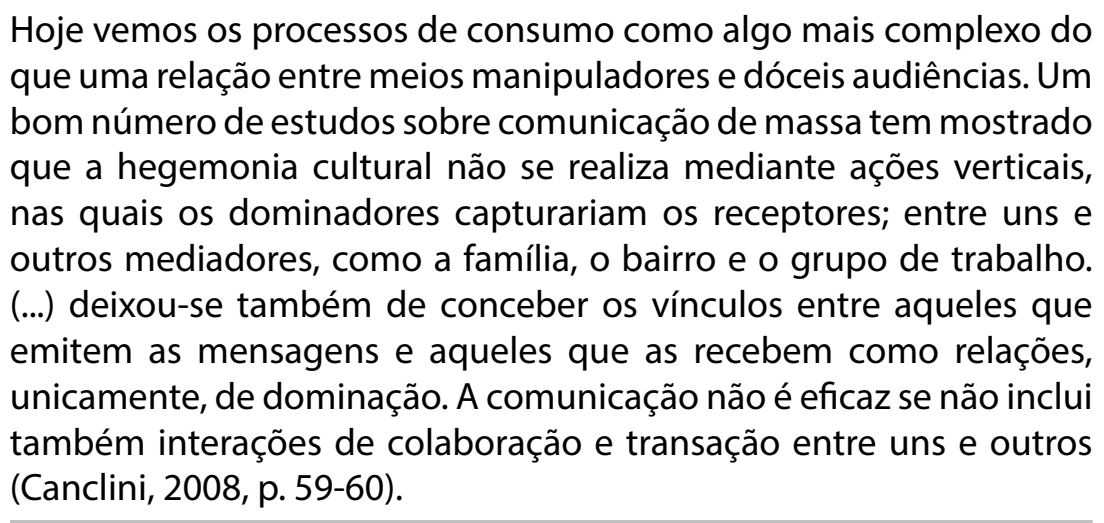

Além disto, a presença semanal durante anos a fio frente à tela do cine Real e o continuo consumo de filmes produzidos no decorrer de mais de três décadas desde o advento das películas sonoras serviu como uma espécie de improvisado curso de história do cinema. Esta circunstância deixou marcas indeléveis em vários aspectos da trajetória de vida e, em pelo menos dois casos, na trajetória profissional dos cinco colaboradores. Se todos continuam cinéfilos e cultuadores dos filmes antigos a ponto de empenharem parte significativa de seus recursos na constituição de coleções particulares de DVD's e Blu-Rays, dois deles, acredita-se - não por acaso - dedicam-se a atividades ligadas ao universo fílmico, um como produtor cultural e outro como docente universitário.

\section{Considerações}

O cine Real foi a última das grandes salas de exibição de rua inaugurada em São Caetano do Sul. O início do seu declínio e de todas as salas de cinema 
localizadas nas ruas das cidades brasileiras é datado do ano de 1968, quando o projeto econômico do governo militar, conhecido como "milagre brasileiro" favoreceu parte dos trabalhadores especializados, permitindo que muitos deles adquirissem aparelhos de televisão e eletrodomésticos pagos em parcelas. Paralelamente a isto, em 1965, foi inaugurada a Rede Globo de Televisão que, graças ao apoio governamental, em poucos anos passou a transmitir para praticamente todo o território nacional. O novo polo privilegiado de lazer passou a ser o aparelho de televisão, ostentado com orgulho na sala das casas operárias.

As novas circunstâncias afastaram paulatinamente as camadas subalternas dos cinemas que, frente ao declínio de público, viu-se na contingência de anunciar filmes apelativos, nos quais a nudez passou a ser frequente. $O$ cine Real incluiu na sua programação filmes proibidos de serem veiculados pela televisão, como por exemplo, a então lançada produção nacional Esta noite encarnarei no teu cadáver (1967), a qual permaneceu durante semanas em exposição na tela por dois motivos básicos: o primeiro era a apresentação de corpos nus e, o segundo, o fato de uma das atrizes que revelava sua nudez ser Tânia Mendonça, uma mulher voluptuosa que pouco tempo antes havia sido coroada miss São Caetano do Sul.

A agonia do cine Real deu-se durante uma década. As pornochanchadas e as fitas propriamente pornográficas foram atraindo cada vez menos interessados e em 1978, finalmente, a sala foi fechada, sendo o recinto ocupado no decorrer dos anos por uma discoteca, uma pizzaria e, por fim por uma igreja evangélica. Mais recentemente, o prédio foi desocupado, encontrando-se atualmente abandonado e em ruínas. O que fora o principal centro de encontro e sociabilidade da comunidade, além de janela cultura para o mundo, hoje é um estorvo que a vila Nova Gerty deseja que seja demolido.

A morte do cine Real foi acompanhada pelo fim de todos os cinemas de rua de São Caetano do Sul, existindo agora apenas acanhadas salas de cinema incrustrada em um shopping center. $O$ que restou dos cinemas suburbanos reside sobretudo na memória dos mais velhos e nos parcos frutos de esforços esporádicos dos órgãos públicos municipais em preservar alguns dados sobre aqueles estabelecimentos, conferindo sentido e importância à recorrência à autoetnografia. No entanto, a importância para a vida daqueles que frequentaram, na meninice, as salas como a do cine Real, é inegável. Eles ainda sonham e vivem o que assistiram há mais de meio século; eles ainda fantasiam que um dia as noites de sábado serão tão especiais como aquelas que um dia eles experimentaram. 


\section{Referências}

AGUIAR, José Vicente. Manaus: praça, café, colégio e cinema nos anos 50 e 60. Manaus: Valer/Governo do Estado do Amazonas, 2002.

BARCINSKI, André e FINOTTI, Ivan. Maldito: a vida e o cinema de José Mojica Marins, o Zé do Caixão. São Paulo: 34, 1998.

BOHRER, Karl Heinz. O ético no estético. In: ROSENFIELD, Denis (Org.). Ética e estética. Rio de Janeiro: Jorge Zahar, p. 9-22, 2001.

BOSI, Ecléa. Memória e sociedade: lembranças de velhos. São Paulo: T.A. Queiroz, 1994.

CANCLINI, Néstor García. Consumidores e cidadãos: conflitos multiculturais da globalização. 7. Ed. Rio de Janeiro: UFRJ, 2008.

CANEVACCI, Massimo. Antropologia do cinema: do mito à indústria cultural. São Paulo: Brasiliense, 1984.

CLIFFORD, James. Sobre a autoridade etnográfica. In:

A experiência etnográfica: a antropologia e literatura no século. Rio de Janeiro: UFRJ, p. 6399, 1998.

DEL CAIRO, Carlos; JARAMILLO MARÍN, Jefferson. Clifford Geertz y el ensamble de un proyecto antropológico. Tabula Rasa, Bogotá, n. 8, p. 15-41, jan./jun. 2008. Disponível em: <http://www.revistatabularasa.org/numero-8/cairoJaramillo. pdf>. Acesso em: 21 ago. 2014.

GABLER, Neal. Vida: o filme. São Paulo: Companhia das Letras, 2000.

GASTAL, Susana. Salas de cinema: cenários porto-alegrenses. Porto Alegre: Unidade, 1999.

GUIMARÃES, Eros Sester Prado. Cinefilia \& gueto: notas sobre uma (auto)etnografia em um cinemão paulistano. In: III Seminário Internacional Enlaçando Sexualidades, 2013. Salvador, Anais..., p. 1-16. Disponível em: <http://www.academia. edu/4004593/Cinefilia and gueto - Notas sobre uma auto etnografia em um cinemao paulistano>. Acesso em: 15 ago. 2014.

KERCKHOVE, Derrick de. A pele da cultura: investigando a nova realidade eletrônica. São Paulo: Annablume, 2009.

KISHIMOTO, Alexandre. A experiência do cinema japonês no bairro da Liberdade. 2009. 390 f. Dissertação (Mestrado em Antropologia Social) - Faculdade de Filosofia, Letras e Ciências Humanas, USP, São Paulo, 2009.

LÓPEZ QUINTÁS, Alfonso. La experiencia estetica y su poder formativo. Bilbao: 
Deusto, 2010.

MARTINS, José de Sousa. Subúrbio: vida cotidiana e história no subúrbio da cidade de São Paulo. 2. ed. São Paulo: Hucitec, 2002.

MOURA, Bruna; LIMA, Caio; NASCIMENTO, Vanusa. Cenas do passado: história das salas de cinema de São Caetano do Sul. 2012. 50 f. Monografia (Trabalho de conclusão de curso em Comunicação Social) - Faculdade de Comunicação Social, UMSC, São Caetano do Sul, 2012.

RANCIÈRE, Jacques. A fábula cinematográfica. Campinas: Papirus, 2013.

RELAÇÃO de cinemas antigos de rua no Brasil em atividade nos anos 60 - São Caetano do Sul (2013). Disponível em: <http://cinemafalda.blogspot.com.br/2009/12/ sao-caetano-do-sul.html >. Acesso em: 25 ago. 2014.

REYNOSO, Carlos. El lado oscuro de la descripción densa: diez años después (2005). Disponível em: <http://carlosreynoso.com.ar/archivos/carlos-reynoso-el-ladooscuro-de-la-descripcion-densa-version-2007.pdf>. Acesso em: 28 ago. 2014.

RUFINI, Claudinei. Os passatempos prediletos. Revista Raízes. São Caetano do Sul, n. 3, p. 39-42, jul. 1990.

SCRIBANO, Adrian; SENA, Angélica de. Construción de conocimento em latinoamerica: algunas reflexiones desde la auto-etnografía como estratégia de investigación.

Cinta de Moebio, n. 34, p. 1-15, mar. 2009. Disponível em: <http://www.scielo. cl/scielo.php?script=sci arttext\&pid=S0717-554X2009000100001\&lang=pt $>$. Acesso em: 15 ago. 2014.

SIMÕES, Inimá Ferreira. Salas de cinema em São Paulo. São Paulo: PW Editores; Secretaria Municipal de Cultural; Secretaria de Estado da Cultura, 1990.

WATSON, Julia. Toward an anti-metaphysics of autobiography. In: FOLKENFLIK, Robert. (Ed.). The culture of autobiography: construction of self-representation. Stanford: Stanford University Press, p. 57-79, 1993.

Recebido em 08 de novembro de 2014.

Aceito em 30 de janeiro de 2015.

Endereço do Autor:

Cláudio Bertolli Filho <cbertolli@uol.com.br>

Universidade Estadual Paulista

Departamento de Ciências Humanas da FAAC

Av. Eng. Luiz Edmundo Carrijo Coube, 1401

Bauru, SP - CEP 17033-360 